\title{
The Number of Economic Relations Analysis of Regional per Capita GDP and Quality Level in China
}

\author{
Wuyi Zhang $1^{\text {st }}$ \\ Quality Development Institute \\ Kunming University of Science and Technology \\ Kunming, China \\ e-mail: wuyi20000@yahoo.com.cn
}

\author{
Yunfei Yang $2^{\text {nd }}$ \\ Faculty of Management and Economics \\ Kunming University of Science and Technology \\ Kunming, China \\ e-mail: 845735130@qq.com
}

\begin{abstract}
This paper regarded the quality management level of regional pillar industries as the average level of regional quality, and selected the quality level of representative seven provinces of China as samples. By drawing scatter diagram and doing the fitting analysis, we ultimately find out the relation of regional per capita GDP and quality level in China: the per capita GDP will increase by 72,870 yuan as soon as the quality level increases by 1 sigma; the improvement of quality level will prompt the diversification of per capita GDP.
\end{abstract}

Keywords- six sigma management theory; per capita GDP; quality level; regression analysis.

\section{INTRODUCTION}

Six sigma management is a kind of management thinking which pursues the improvement of quality level through optimizing the internal process, which is commonly represented by Greek letters $\sigma$. In the field of quality management, how to represent the level of quality control, which depends on the number of the sigma of product variation within standard upper and lower limits, if it is controlled in $3 \sigma$, it will represent that the product pass rate is not less than $99.73 \%$; on the contrary, if controlled in $6 \sigma$, it will represent that the product fraction defective is not more than $0.002 \mathrm{ppm}$, which represents the defective goods are not more than 0.002 per one million products too. In practice, although there is a 1.5 fluctuation between the actual sigma level and the theoretical value, there are only 3.4 unqualified products in one million products under $6 \sigma$, which is close to zero defect level ${ }^{[1]}$.
In the 1960s, Japan introduced the idea of quality control from the United States, meanwhile, each of Japan's community conscientiously studied and implemented it, which has made great progress to the quality level of product ${ }^{[2]}$. In the late 1970 s and early 1980s, Japan seized great market share from America's enterprises, which led MOTOROLA Corporation to lose some market. In order to reduce quality fluctuation and improve product quality, MOTOROLA Corporation ambitiously proposed to control the product quality above the $6 \sigma$, thus the 6 sigma management method appeared ${ }^{[3]}$. After six sigma was applied to some enterprises, they had summed up some classic dissertations such as the "quality free", "quality improves welfare" and so on. Owing to these discussions are research conclusions for enterprises and other microstructure, however, are these conclusions suitable for the competition and development of regional economics? Therefore, this paper takes regional per capita GDP as the comprehensive results of regional competition and development ability so as to explore the relationship between the regional per capita GDP and quality level.

This paper regarded quality level as the measure of regional quality level. Owing to be lack of related data about regional quality level, we took the pillar industries' radioactive and correlation to the regional industries' development into consideration, and regarded the quality level of regional pillar industries as behalf of the regional average quality level. 


\section{II.CALCULTION OF AREA QUALITY LEVEL}

Quality management level can be measured by sigma level. Sigma level depends on the eligible rate of sampling products and the process quantity of final products, their mathematical relationship can be shown as below:

\section{$\mathrm{Z}=100 *$ NORMSDIST $^{\mathrm{n}}$}

Including: $\quad \mathrm{Z}$ - Eligible rate of sampling products;

NORMSDIST- Normal accumulation distribution function;

$\sigma$ - Sigma level;

$\mathrm{N}$ - The processes of final products;

Seen from the formula (1), we would calculate the sigma level of molding products if the eligible rate of sampling products $(\mathrm{Z})$ and process $(\mathrm{N})$ were known, in addition, the data of $\mathrm{Z}$ and $\mathrm{N}$ can be achieved in the General Administration of Quality Supervision, the official website of the provincial Bureau of Quality Supervision and related literature. Then we analyzed and studied the regional quality level of Tianjin in North China, Shanghai in East China, Guangdong in South China, Hubei in Central China, Shanxi in Northwest China, Yunnan in Southwest China and Heilongjiang in Northeast China.

According to the data of central government portal, as the region's traditional industry in Tianjin, the textile industry has attracted much attention among government departments, and it always retains its position as one of the eight pillar industries in Tianjin. Therefore, we took the quality level of the textile industry in Tianjin as the representative of regional quality level. According to the published data of Quality Inspection Bureau in Tianjin, the sampling qualified rate of textile industry in Tianjin was $99.12 \%$, and the main production process of textile had 6 steps ${ }^{[4]}$ : (1) fiber manufacturing; (2) spinning; (3) weaving; (4) dyeing and printing; (5) fabric dressing; (6) textile packaging. According to the formula (1), we can calculate the quality level of textile industry in Tianjin in $3.4 \sigma$ or so.

Shanghai's automobile manufacturing industry is the pillar industry of the region, and this paper took the industry as the representative of the quality level in Shanghai. According to the published data of Quality Inspection Bureau in Shanghai, the sampling qualified rate of auto manufacturing in Shanghai was $99.67 \%$, in addition, the production processes of automobile was relatively complex, and the main production process had 10 steps $^{[5]}$ : (1) mapping, as well as drawing appearance of the car; (2) making molds according to the pattern; (3) the stamping of finished molds; (4) the design of circuit; (5) forging or casting the Auto parts; (6) the welding work of high quality; (7) painting; (8) installing; (9) the landscaping work of components; (10) commissioning work. According to the formula (1), we can calculate the quality level of automobile manufacturing industry in Shanghai in $3.6 \sigma$ or so.

The main pillar industry is the automobile manufacturing industry in the region of Guangdong. This paper regarded the industry as the representative of quality level in Guangdong. According to the published data of Quality Inspection Bureau in Guangdong, the sampling qualified rate of auto manufacturing in Guangdong was $99.67 \%$, and the main production processes in Guangdong which were the same as the production processes in Shanghai had 10 steps ${ }^{[6]}$. According to the formula (1), we can calculate the quality level of automobile manufacturing industry in Guangdong in 3.2 sigma level or so.

Hubei is an important production base of iron and steel as well as non-ferrous metals in China, the industry of iron and steel as well as nonferrous metal is one of the eight pillar industries in Hubei. According to the published data of Quality Inspection Bureau in Hubei, the sampling qualified rate of iron and steel industry in Hubei was $97.67 \%$. The main production processes had 8 steps

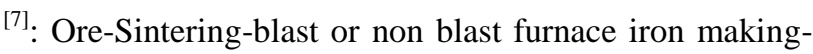
the pretreatment of hot metal - steelmaking - refiningcontinuous casting and rolling. According to the formula (1), we can calculate the quality level of iron and steel industry in Hubei in 3 sigma level or so.

According to the official website announced that the automotive industry have finished 120 billion yuan of gross output value from January to June in 2010, increased by $37.5 \%$, and become one of the pillar industries of the high-speed development, so we took this industry as the representative of quality level in Shanxi. According to the published data of Quality Inspection Bureau in Shanxi, the sampling qualified rate of auto 
manufacturing in Shanxi was $95.67 \%$, its main production processes were the same as described above ${ }^{[8]}$. According to the formula (1), we can calculate the quality level of automobile manufacturing industry in Shanxi in 2.8 sigma level or so.

Tea is an important pillar industry in "two strong fort" strategy in Yunnan. According to the published data of Quality Inspection Bureau in Yunnan, the sampling qualified rate of tea industry was $97.27 \%$, the main production process of tea had 7 steps(picking, spreading, fixing, carding, modeling, drying and storing) [9] . According to the formula (1), we can calculate the quality level of tea industry in Yunnan in 2.7 sigma level or so.

There are four pillar industries in Heilongjiang Province, four pillar industries have achieved the main business income about 238.7 billion yuan from January to April in 2010, which has increased by $41.6 \%$ compared with the same period. In a word, we took the industry of petrochemical products as the representative of quality level in Heilongjiang. According to the published data of
Quality Inspection Bureau in Heilongjiang, the sampling qualified rate of petrochemical industry was $99.17 \%$, and the main production processes of petrochemical industry had 12 steps ${ }^{[10]}$ : (1) the exploitation of crude oil; (2) the desalting and dehydration of crude oil; (3) atmospheric and vacuum distillation; (4) the thermal cracking; (5) catalytic cracking; (6) the catalytic reforming; (7) aromatics extraction; (8) coking (9) delayed coking; (10) hydrocracker; (11) refinery gas processing; (12) refining of petroleum products. According to the formula (1), we can calculate the quality level of petrochemical industry in 3 sigma level or so in Heilongjiang.

According to the above analysis about Tianjin in North China, Shanghai in East China, Guangdong in South China, Hubei in Central China, Shanxi in Northwest China, Yunnan in Southwest China and Heilongjiang in Northeast China, we finally get the quality level of the above 7 provinces. As shown in table 1 :

TABLEII. REGIONAL QUALITY LEVEL

\begin{tabular}{|c|c|c|c|c|c|c|c|}
\hline Region & Tianjin & Shanghai & Guangdong & Hubei & Shanxi & Yunnan & Heilongjiang \\
\hline Quality Level $(\sigma)$ & 3.4 & 3.6 & 3.2 & 3 & 2.8 & 2.7 & 3 \\
\hline
\end{tabular}

\section{ANALYSIS OF REGIONAL PER CAPITA GDP}

This paper chose the regional economic data in 2010, which mainly came from China statistic yearbook in 2010 .
We can get regional per capita GDP from the formula: regional per capita GDP $=$ the total GDP of the region /regional population, as shown in table 2:

tableiII. The Value Table of Regional Per Capita Gdp

\begin{tabular}{|l|c|c|c|c|c|c|c|}
\hline \multicolumn{1}{|c|}{ Region } & Tianjin & Shanghai & Guangdong & Hubei & Shanxi & Yunnan & Heilongjiang \\
\hline $\begin{array}{l}\text { Total GDP (One hundred million } \\
\text { yuan) }\end{array}$ & 7521.9 & 15046.5 & 39482.6 & 13240.4 & 8169.8 & 6169.8 & 8587 \\
\hline $\begin{array}{l}\text { Population (ten thousand people) } \\
\text { Per capita GDP ( ten thousand } \\
\text { yuan/per capita) }\end{array}$ & 1228 & 1921 & 9638 & 5720 & 3772 & 4571 & 3826 \\
\hline
\end{tabular}

Note: The unit of per capita GDP is ten thousand yuan/per capita 
IV. THE NUMBER OF ECONOMIC

\section{RELATIONS ANALYSIS OF REGIONAL PER}

\section{QUALITU LEVEL}

We took the sigma value of quality level as independent variable $\mathrm{x}$ and the regional per capita GDP as dependent variable $y$, which can analyze scatter

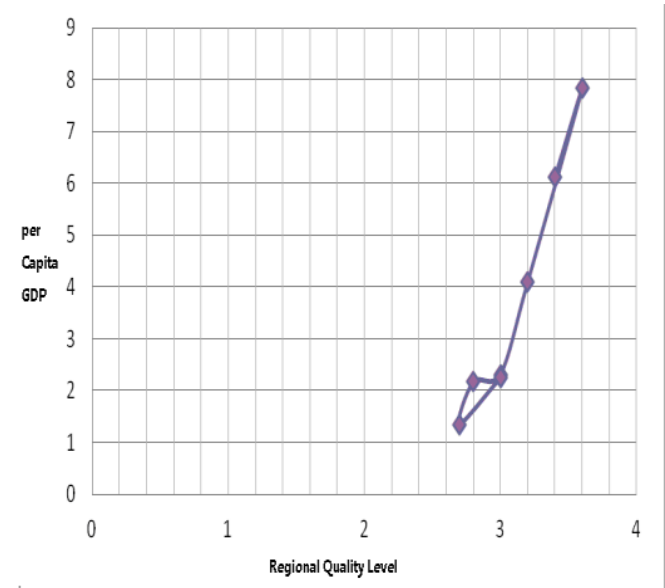

Figure1. Scatter distribution between regional quality level and per capita GDP

\section{CAPITA GDP AND}

distribution of $\mathrm{x}$ and $\mathrm{y}$ with SPSS software from 8 provinces' quality level of table 1 and per capita GDP of table 2 , as shown in figure 1 :

The Figure 1 shows that per capita GDP(y) presents a remarkable rising trend with the increase of quality level $(\mathrm{x})$, but the rising trend shows nonlinear trend, therefore the curve-fitting method can be considered.

By analyzing the data using Linear fitting, Logarithmic fitting, Inverse fitting, Quadratic fitting, Cubic fitting, Power fitting and exponential fitting with SPSS software, the results can be obtained:

TABLEIV. NUMERICAL FORM OF CURVE FITTING ANALYSIS

\begin{tabular}{|c|c|c|c|c|c|c|c|c|c|}
\hline \multicolumn{10}{|c|}{ Model Summary and Parameter Estimates } \\
\hline \multicolumn{10}{|c|}{ Dependent Variable: per capita GDP $(y)$} \\
\hline \multirow{2}{*}{ Equation } & \multicolumn{5}{|c|}{ Model Summary } & \multicolumn{4}{|c|}{ Parameter Estimates } \\
\hline & $R$ Square & $F$ & $d f 1$ & $d f 2$ & Sig. & Constant & $b 1$ & $b 2$ & $b 3$ \\
\hline Linear & .940 & 78.274 & 1 & 5 & .000 & -18.857 & 7.287 & & \\
\hline Logarithmic & .921 & 58.344 & 1 & 5 & .001 & -21.696 & 22.567 & & \\
\hline Inverse & .899 & 44.408 & 1 & 5 & .001 & 26.268 & -69.230 & & \\
\hline Quadratic & .982 & 111.631 & 2 & 4 & .000 & 38.309 & -29.364 & 5.821 & \\
\hline Cubic & .962 & 107.244 & 2 & 4 & .000 & 19.132 & -11.014 & .000 & .612 \\
\hline Power & .957 & 112.299 & 1 & 5 & .000 & .003 & 6.034 & & \\
\hline Exponential & .960 & 119.016 & 1 & 5 & .000 & .008 & 1.931 & & \\
\hline
\end{tabular}

The final fitting regression figure of all kinds of curve models are given below: 


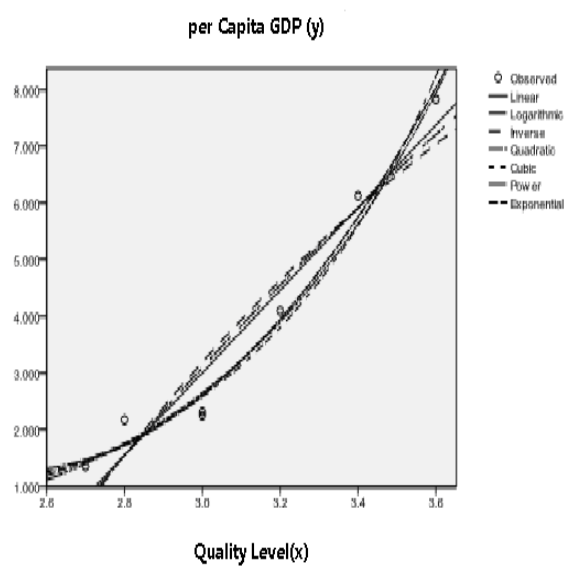

Figure2. Curve regression model
Other fitting models' coefficient of determination is either not high or can't be explained from the perspective of economics. So linear fitting and quadratic fitting are used here.

The analysis can be obtained from Table 3:

Linear fitting equation of $\Psi$ and $\Xi: \quad \Psi=7.287 \Xi-18.857$

Quadratic fitting equation of $\Psi$ and $\Xi: \quad \Psi=-229.364 \Xi+5.821 \Xi^{2}+38.309$

Derivation of model (3): $\Psi \supseteq=11.642 \Xi-29.364$

Table 3 shows that: even though both of the above two models have prominent economic significance, the coefficient of determination of quadratic curve reaches 0.982, which covers almost all of the information. Therefore the fitting effect of quadratic curve is more appropriate than linear curve.

Marginal GDP can be got from the derivation of model (2), In other words, when the independent variable improves more than $1 \sigma$, the per capita GDP of the dependent variable will increase correspondingly. From model (2), we can infer that: on the premise of quality management level at present in China, the per capita GDP will increase by 72.287 thousand yuan if $1 \sigma$ level is improved. The modern quality level is between $2.5 \sigma$ and $3.5 \sigma$ in China, we need introduce modern means and methods of quality management instead of largely increasing investment in hardware, such as the application of quality management, the improvement of enterprise management and so on. At present, China's overall quality level is considered as $3 \sigma$ and the total population is about 1.317 billion, therefore, the total amount of China's GDP will increase more than 90 trillion yuan if $1 \sigma$ level is improved. In addition, according to the actual situation of Chinese enterprises, although it is difficult for some small and medium enterprises to improve $1 \sigma$ quality level at present, improving 0.1 sigma quality level will be easy to come true for most of them if they use the method of quality management reasonably and improve their comprehensive management level, furthermore, the total amount of China's GDP will increase more than 9 trillion, which will make a great contribution to our comprehensive economic strength. In conclusion, improving the level of quality management is significant to increase and prompt our comprehensive economic strength.

The reports of the18th National Congress of the Communist Party of China put forward that it was necessary to speed up the formation of new economic development mode, moreover, the foothold of promoting the economic development would be transferred to improve quality and efficiency. Quality improving efficiency would be inevitable requirement for implementing the scientific concept of development, which further pointed out the path of enhancing China's long-term development. According to analyzing the relationship of quality level and GDP, if enterprises change the mode of economic development and pay attention to management level, they will improve quality level, and then promote economic growth and increase enterprise efficiency. So the scientific concept of development to increase efficiency through improving quality level will come true completely.

The economics implication for the second derivative model (3) is the marginal rate, and the value is 5.281>0, which shows that the marginal per capita GDP increases 
progressively and the growth of sigma level accelerates and prompts per capita GDP, in other words, the higher the sigma level is, the higher the contribution to GDP becomes. Therefore, quality level is the vital reason for the gap between the developed and the developing. GDP per capita and the total GDP are significant factors to value a country's development degree. Quality management level makes a great devotion to GDP's development. Furthermore, the quality level of the developed is higher than the developing generally, however, the quality level accelerates and prompts per capita GDP obviously, so the bigger the disparity of quality level is, the bigger the gap of GDP becomes,

\section{V.SUMMARY}

This paper researched on the number of economic relations of 7 representative provinces' quality level ( $\sigma$ ) and their per capita GDP based on empirical analysis, as well as used SPSS statistical software to analyze their scatter analysis and regression analysis, therefore, we draw the following conclusions by inferring the number of their economic relations:

(1) The per capita GDP will increase by 72.287 thousand yuan if $1 \sigma$ level is improved. To improve the quality level by improving management level, which is feasible to increase the quantity of GDP and carry out the which results in obvious gap of the GDP and the developed degree between the developed and the developing. All in all, we should transfer the mode of economic development and improve the management level to narrow the gap with the developed. Only in this way can we improve the quality level and achieve the economic growth.

Model (4) shows: China's quality management level of the most of enterprises have surpassed $2.52 \sigma$ except some small and medium ones at present, in other words, it needs to be more than or equal to $2.52 \sigma$,only in this way can it make contribution to the economic industry.

thinking of quality and efficiency of the18th National Congress of the Communist Party of China.

(2) Quality level plays an important role in increasing GDP. In addition, we also summarize that the gap of quality level is a significant factor to differ the developed from the developing.

This paper took China's representative pillar industry of 7 provinces as simples. Maybe it was not enough in data collection, and the fitting model may also have some deviations compared with ideal situation, but we will continue to enrich and improve in the later study.

\section{ACKNOWLEDGEMENT}

Fund Project: Reserve talents fund for young and middle-aged academic technology leader in Yunnan Province; Fund Code: 2010CI010

\section{REFERENCES}

[1] Joseph Juran. Juran's Quality Handbook[M]. The Press of Renmin University of China, 2003

[2] Liu Zhongmin, Gao Yueting, etc. Application Research on $6 \sigma$ Quality Management Method in the Quality Control of Clinical Laboratory $[\mathrm{J}]$. Laboratory Medicine, 2010, 25(3): 224-227.

[3] Li Yuanyuan, li Ping, etc. Apply Six Sigma Quality Management to Assess the Quality Performance of Clinical Laboratory and Design Quality Control[J].China Medical Devices Information, 2007, 13 (6): 9-12.

[4] What Are the Production Processes of Textiles [EB/OL]. http://www.gzgmdl.com/.
[5] Manufacturing Technology of Automobile [EB/OL]. http://baike.baidu.com/view/3424640.htm

[6] Manufacturing Technology of Automobile [EB/OL]. http://baike.baidu.com/view/3424640.htm

[7] Iron and Steel Manufacturing Process [EB/OL] http://wenku.baidu.com/view/1ec86b1514791711cc7917d8.html

[8] Manufacturing Technology of Automobile [EB/OL] http://baike.baidu.com/view/3424640.htm

[9] Manufacturing Technology of Spring Tea [EB/OL] http://www.05760576.com/Article/ls/feiyi/201012/2989.html

[10] Oil Refining [EB/OL]. http://bbs.hcbbs.com/thread-130700-1-1.html 